\title{
Study of Radioactivity and its Impact Activity in the District of al-Qasim / Babil Province
}

\author{
Oday H. R. Al-Bodairy ${ }^{1}$, Eshraq M. Hassan ${ }^{2}$, Meha Riyadh ${ }^{3}$ \\ ${ }^{1,2}$ Department of Physics, College of Sciences, University of Babylon
}

\begin{abstract}
In this research study the level of background radiation for four selected areas of soil the district of al-Qasim/Babil province by using the counting system and electronic analysis to detect radiation gamma and the detector $\mathrm{NaI}(\mathrm{Tl})$ radionuclide resulting from the dissolution chains of $238 \mathrm{U}$ and $232 \mathrm{Th}$ ( 214Bi, 214Pb 234Th $226 \mathrm{Ra}, 212 \mathrm{Bi}$ ) are produced in addition to radionuclide potassium individual (40K), the paper also counts the radioactivity of each radionuclide and its concentration within the Sample unit (mg / Kg), and calculate the ratios of natural uranium, depleted uranium, the creation of ratio between $238 U / 235 U$, Where results proved the presence of varying proportions of depleted uranium contamination of the sites $(1,3,4)$, ranging between $\left(0.005466 \_0.006456\right)$, which is located within the limits allowed by the International Atomic Energy Agency, (0.0046).
\end{abstract}

Keywords: Radioactivity, Radiation Gamma, Natural Uranium

\section{Introduction}

The typical radioactivity researches for many places in Iraq were done by many workers for a soil samples Al_Saji in 1999 [1],studied the effect of the radioactive wopens on the water south of Iraq and the found the ${ }^{226} \mathrm{Ra}$ isotope. In 2000, Nashwan Shewket [2] the radioactive pollution in Neinow province and found ${ }^{226} \mathrm{Ra}$ and ${ }^{137} \mathrm{Cs}$ concentration more than the natural level. In 2001 [3], Al

Kinany studied the radioactivity pollution with the depleted uranium in a Basra province and he calculated the ${ }^{235} \mathrm{U} /{ }^{238} \mathrm{U}$, the results shows a pollution with different ratios . Al_Gurabi 2002 [4] , show that on increase in the radioactive pollution in the south of Iraq . In 2003 [5], Murtada Shaker studied the radioactivity for the water in Babylon province and the results shows on existence some isotopes belong to ${ }^{238} \mathrm{U}$ and ${ }^{232} \mathrm{Th}$ series . In 2004 [6] Al_Baiaty studied the concentration of the depleted uranium and the radioactive pollution in the soil samples in Al Tamim province. In 2005 [7], Al_Azawi calculated the ${ }^{\overline{23} 4} \mathrm{Th}$ and ${ }^{235} \mathrm{U}$ concentrations and the ${ }^{235} \mathrm{U} /$ ${ }^{238} \mathrm{U}$ ratio in Al_Basra south of Iraq.

The aim of the present work is study radioactive background in different places in district of al-Qasim / Babil province, middle of Iraq and determine the type and the concentration for the radioactive nuclides.

\section{The Nuclear Detector System}

In the present work, the nuclear detection system, figure ( 1 ), type ( UCS 30) ( Spectrum Techniques LLC ) with $\mathrm{NaI}(\mathrm{Tl})$ size of crystal $(3,8 \times 2.5 \mathrm{~cm})$

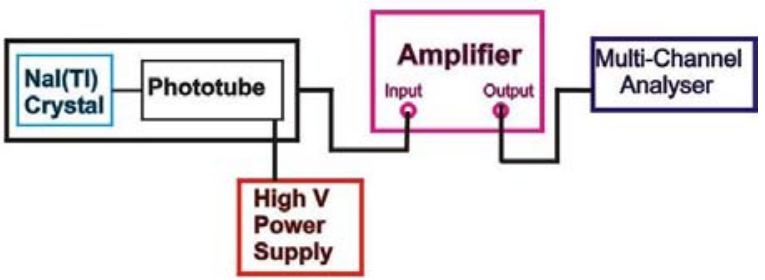

Figure 1: Detection system used
The $\mathrm{NaI}(\mathrm{Tl})$ detector consist of two pants , the $\mathrm{NaI}(\mathrm{Tl})$ crystal and the photo multiplier, the detection system consist of two amplifiers, pave and main, the job of this amplifiers is shaping the electronic signal, amplification and release the electronic noise . The electronic signals go to the multichannel analyzer and show the result as an energy spectrum as shown in figure (2) [8].

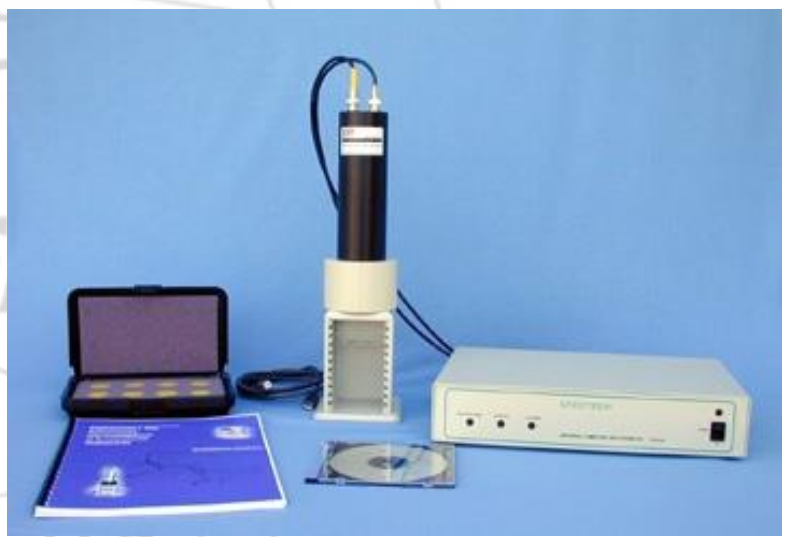

Figure 2: Parts of the system Detect

\section{The Detection System Calibration}

Two calibration were done for the gamma ray nuclear detection system, the first for the detection efficiency and the second is the energy, by using a standrad radioactive sources putted in a container of $0.25 \mathrm{~L}$ volume. The calculate efficiency $(\xi)$ is given by [9].

$$
\xi=\frac{N / T}{A . I \gamma}
$$

$N$ : count rate under photo peak position .

$T$ : time measurement .

$A$ : activity of radioactive sources using of calibration .

$I_{\gamma}$ : relative intensity of each energy source of the energies of the radioactive 


\section{International Journal of Science and Research (IJSR) \\ ISSN (Online): 2319-7064}

Index Copernicus Value (2013): 6.14 | Impact Factor (2015): 6.391

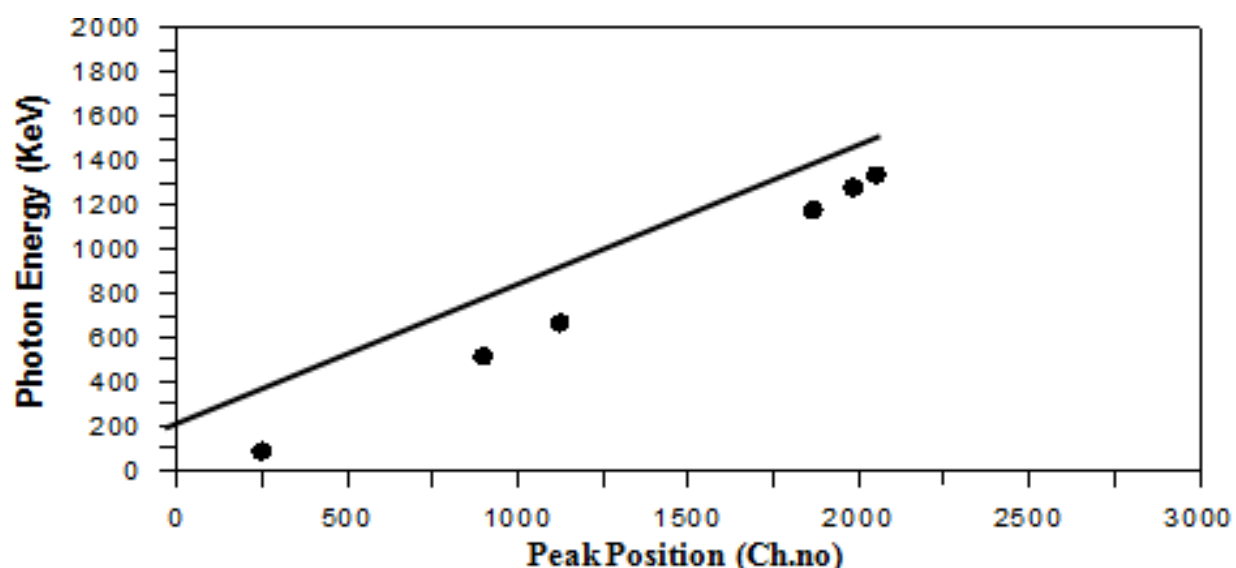

Figure 3: Calibration system energy

And the energy resolution (ER) is given by, fig. (3), by using ${ }^{60}$ Co source [9] .

\section{$E . R=\frac{F \cdot H \cdot W \cdot M}{\text { Chno. }} x 100 \%$ \\ F.W.H.M : Full width high maximum. \\ Ch .no : photo peak position .}

\section{The soil samples preparation}

Four selected places from different region in Babylon province, middle of Iraq, figure ( 4 ) show the map of Babylon province. The soil samples prepared for the detection.

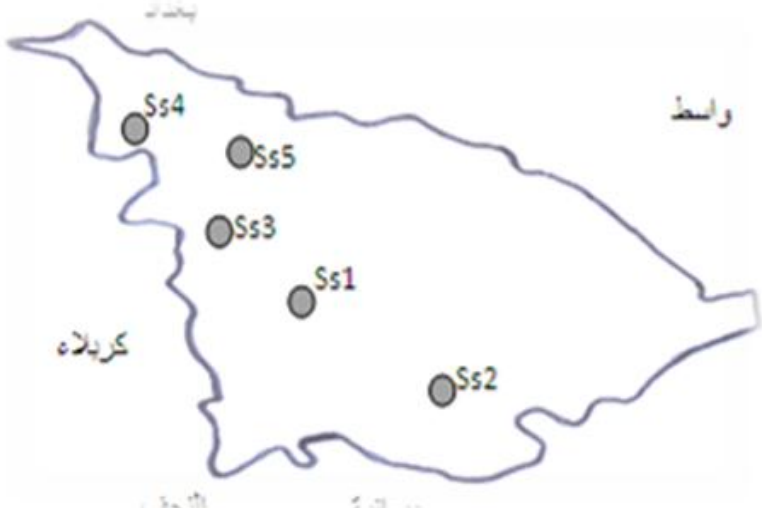

Figure 4: The region selected in the studied

\section{The radioactive samples test}

The radiation background (B.G) were calculated to sub it from the energy spectrum for the studied sample as in following equation [10].

$$
\text { B. } G(B q)=\frac{\text { Area }}{L_{Y} q 6 \xi \% 6 T} \times 100 \%
$$

The specials radioactivity was calculated for each sample with (18000) s time and it calculated from [11]:

$$
\text { Specific Activity }=\frac{A r e d / T-B . G}{L_{Y} 96 \% 96 m} \times 100 \%
$$

Where :

Area : net area under the photo peak position . $m$ : mass of sample unit $(\mathrm{Kg})$.

\section{Calculated the Ratio between ${ }^{235} U /{ }^{238} U$}

The radioactivity per $1 \mathrm{mg}$ of ${ }^{238} \mathrm{U}$ is given by $[6,12]$. $A c=\lambda N$

$A_{c}:$ Radioactivity unit $(\mathrm{Bq})$

$\lambda:$ Decay constant $=\ln 2 / \mathrm{t}_{1 / 2}$

$\mathrm{t}_{1 / 2}$ : half live of ${ }^{238} \mathrm{U}$ isotope

$N$ : number of atoms and is given by of the equation :.

$N=N o(W) / A$.

$N_{0}$ : Avocado number .

$W$ : mass of isotope unit $(\mathrm{Kg})$.

$A$ : mass number of isotope radioactivity .

And one can calculated the radioactivity for ${ }^{238} \mathrm{U}$ series ( Ac ) from the equation following :-

$$
A_{c}=\operatorname{Ln} 2 / t_{1 / 2} \times N o \times W / A
$$

That Ac from equation $(7)$ is $(12,35 \mathrm{~Bq})$.

To calculate the percentage for depleted uranium ( $\mathrm{X} \%$ ) in the soil samples, one can use the following equation [9] :

$X \%=D U(m g / k g) / C s U-238(m g / k g) \times 100$

Where :

$D U$ : Quantity of depleted uranium is found that in a soil sample.

$C s U$ : Concentration $238 \mathrm{U}$ in a soil sample of unit $(\mathrm{mg} / \mathrm{Kg})$.

And to gut the ${ }^{235} \mathrm{U} /{ }^{238} \mathrm{U}$ ratio ( $\mathrm{Ru}$ ) for the soil contain the natural uranium of ${ }^{238} \mathrm{U}$ with $99.2745 \%$ ratio and ${ }^{235} \mathrm{U}$ with $0.72 \%$ ratio and ${ }^{234} \mathrm{U} 0.0054 \%$ ratio and depleted uranium contain an increase of ${ }^{238} \mathrm{U}$ with $0,35 \%$, and decrease ${ }^{235} \mathrm{U}$ ratio with the same quantity we can find it by the following equation .

$$
R u=\frac{0.72-0.37 X}{99.2745+0.3755 X}
$$

Where :

$\mathrm{X}$ : Ratio of depleted uranium in a soil sample .

\section{The Results}

In the present work, the determination of the radioactive nuclides resulting from decay of the ${ }^{238} \mathrm{U},{ }^{232} \mathrm{Th}$ series and the single ${ }^{40} \mathrm{~K}$ nuclide and ${ }^{137} \mathrm{Cs}$, and the specific radioactivity for 


\section{International Journal of Science and Research (IJSR) \\ ISSN (Online): 2319-7064 \\ Index Copernicus Value (2013): 6.14 | Impact Factor (2015): 6.391}

the $(1,2,3,4)$ samples were done and the results shown in the table $(1)$.

Table ( 1 ) radioactivity of the soil sample $(1,2,3,4)$

\begin{tabular}{|c|c|c|c|c|c|c|}
\hline 4 & 3 & 2 & 1 & Number of Sample & \multirow{3}{*}{$\begin{array}{l}\text { Energy } \\
\text { K(eV) }\end{array}$} & \multirow{3}{*}{$\begin{array}{c}\text { Nuclide } \\
\text { radioactive }\end{array}$} \\
\hline S4 & S3 & S2 & S1 & Region & & \\
\hline & & & & Ratio between ${ }^{226} \mathrm{Ra}{ }^{234} \mathrm{Th}$ & & \\
\hline 0.958 & 0.897 & 0.812 & 0.894 & \multirow{7}{*}{$\begin{array}{l}\text { Radioactivity of unit }(\mathrm{Bq} \\
\qquad / \mathrm{Kg})\end{array}$} & 40 & ${ }^{212} \mathrm{Bi}$ \\
\hline 4.230 & 11.223 & 10.112 & 11.778 & & 63 & ${ }^{234} \mathrm{Th}$ \\
\hline 19.128 & 36.286 & 33.796 & 15.108 & & 186.2 & ${ }^{226} \mathrm{Ra}$ \\
\hline 21.476 & 38.204 & 39.013 & 19.568 & & 351.9 & ${ }^{214} \mathrm{~Pb}$ \\
\hline 2.234 & 4.796 & 3.727 & 1.512 & & 609.3 & ${ }^{214} \mathrm{Bi}$ \\
\hline 3.511 & 2.908 & 3.794 & 2.547 & & 1461.5 & ${ }^{40} \mathrm{~K}$ \\
\hline 479.984 & 518.791 & 502.859 & 372.549 & & 40 & ${ }^{212} \mathrm{Bi}$ \\
\hline
\end{tabular}

Also, the natural to depleted uranium and ${ }^{235} \mathrm{U} /{ }^{238} \mathrm{U}$ ratio were calculated and the results shown in table ( 2 ).

Table 2: Ratio between depleted uranium and natural and found that the ratio between ${ }^{235} \mathrm{U} /{ }^{238} \mathrm{U}$

\begin{tabular}{|c|c|c|c|c|c|}
\hline $\mathrm{Ru}$ & $\begin{array}{c}\text { Percent ratio of natural } \\
\text { uranium }(100-\mathrm{X} \%)\end{array}$ & $\begin{array}{c}\text { Percent ratio of depleted } \\
\text { uranium }(\mathrm{X} \%)\end{array}$ & $\begin{array}{c}\text { Concentration depleted } \\
\text { uranium }(\mathrm{mg} / \mathrm{Kg})\end{array}$ & $\begin{array}{c}\text { Concentration } \\
{ }^{238} \mathrm{U}(\mathrm{mg} / \mathrm{Kg})\end{array}$ & $\begin{array}{c}\text { Number of } \\
\text { sample }\end{array}$ \\
\hline 0.005466 & 52.31601 & 47.68399 & 0.919664 & 1.928664 & $\mathbf{1}$ \\
\hline 0.007036 & 94.21707 & 5.782928 & 0.061931 & 1.070931 & $\mathbf{2}$ \\
\hline 0.006456 & 78.7534 & 21.2466 & 0.272215 & 1.281215 & $\mathbf{3}$ \\
\hline 0.005466 & 52.33359 & 47.66641 & 0.919016 & 1.928016 & $\mathbf{4}$ \\
\hline
\end{tabular}

\section{The Discussion result}

In the present work, the study of the specific radioactivity for a selected soil samples in Babylon province middle of Iraq were done for the position $(1,2,3,4)$ It is found that the ratio between the daughters in ${ }^{238} \mathrm{U}$ series in the start of the series decay of values between $\left(0,958 \_0,812\right)$ and it represent to a radiation equilibrium approach to the ideal case ( 1 ). But in the end the decay series it is found radiation equilibrium because of the production of ${ }^{226} \mathrm{Ra}$ gas which result from the decay of the ${ }^{226} \mathrm{Ra}$ isotope .

Also is found that the radioactivity of the $\left({ }^{212} \mathrm{Bi},{ }^{234} \mathrm{Th}\right.$, ${ }^{226} \mathrm{Ra},{ }^{214} \mathrm{Bi},{ }^{214} \mathrm{~Pb}$ ) nuclides are given of the different ratio depend on concentration isotope of the sample and depended on the geological nature of the soil sample.

The radioactivity of potassium nuclide ${ }^{40} \mathrm{~K}$ the highest concentration found in $\mathrm{S} 3(518.791) \mathrm{Bq} / \mathrm{Kg}$ for the presence of agriculture land containing phosphate fertilizer, which increased the concentration of isotope ${ }^{40} \mathrm{~K}$.

Also been I identified radioactive region contaminated areas by calculating the pollution of depilated uranium to natural uranium and to find that the ratio between the ${ }^{235} \mathrm{U}$ ${ }^{238} \mathrm{U}$, as the ratio between then is the nature $(0,0072)$, if the ratio between $(0.00562-0.0072)$, this means that concentration ranging from depleted uranium $\quad(0 \%-40$ $\%)[12,6]$. This is what has been observed in model of the soil, were he found that the sites $(1,3,4)$ contain the quantities and different properties of depleted uranium .

\section{Conclusions}

1) Fond that the ratio ${ }^{235} \mathrm{U} /{ }^{238} \mathrm{U}$ in our measurement of soil sample that the site $(1.3,4)$ rang between $(0.006456-0.005466)$ which indicate the presence varying ratio depleted uranium contamination, which is located within limits allowed by the international atomic energy agency, $(0,0046)[14,15]$.

2) Found that the ratio of ${ }^{234} \mathrm{Th} /{ }^{226} \mathrm{Ra}$ be in the rang $(0.958$ 0.812 ), which indicates the radioactive equilibrium which is approaching the ideal case (1), but did not notice this equilibrium after the radium due to the consumption of radon ${ }^{222} \mathrm{Rn}$ from the container used the measurement of radioactivity specific model .

\section{References}

[1] Al_Saji , M . "Effect production of using radioactive wopens on the water south of Iraq" , Baghdad university ,1992.

[2] Nashwan, Sh . "Pollution radioactivity and source in Neinow province", Baghdad university, 2000 .

[3] Al Kinany, A." Study of depleted uranium in soil sample selected from Al_Basra province" , mathematical and physical journal, No 3 , pp 16, 2001.

[4] Al Gurabi , S.J. "Pollution produced from using wopens contain depleted uranium south of Iraq" , decided first conversation scientific in Iraq, Vol.1 August,2002 .

[5] Murtada .sh.A . "Study radioactivity water in Babylon province" , Babylon university, 2003.

[6] Al_Baiati .SM." Study concentration depleted uranium and pollution radioactivity of the soil sample in Al_Tamim province", 2004.

[7] 7.Souad AL_Azzawi, " Depleted Uranium Radioactive Contamination In Iraq An Overview " ,2005, Technology University .

[8] Al_Dorgzliy ,Sh . " Principle physical nuclear" , 1989.

[9] G. Knoll ; "Radiation Detection and Measurement" John Wiley, U.S.A. 1979

[10] IAEA. Nuclear data standard for nuclear measurements Technical Report Series No. 227,1983 .

[11] IAEA ; "The Environmental Behavior of Radium"; vol.1 ; IAEA ; 1990 


\section{International Journal of Science and Research (IJSR) \\ ISSN (Online): 2319-7064}

Index Copernicus Value (2013): 6.14 | Impact Factor (2015): 6.391

[12] UNEP, "Scientific Mission to Kosovo , Depleted Uranium in Kosovo" , Post Conflict Environment Assessment, 2000.

[13] R, ABleise and Burkart , Danesi, W (IAEA), "Properties, use and health effects of depleted uranium (DU): a general overview " . IAEA, Vienna . Journal of Environmental Radioactivity, 2003.

[14] International group of experts in IAEA." Radiological Conditions in Areas of Kuwait with Residues of Depleted Uranium ". IAEA : Austria , 2003 .

[15] National Council for Scientific Research, Lebanese Atomic Energy Commission . " Investigation of the Possible Depleted Uranium Contamination in Lebonon after the 2006 summer Israeli Attack " . Lebanese Science Journal, Vol. 8, No. 1, pp 145 , 2.

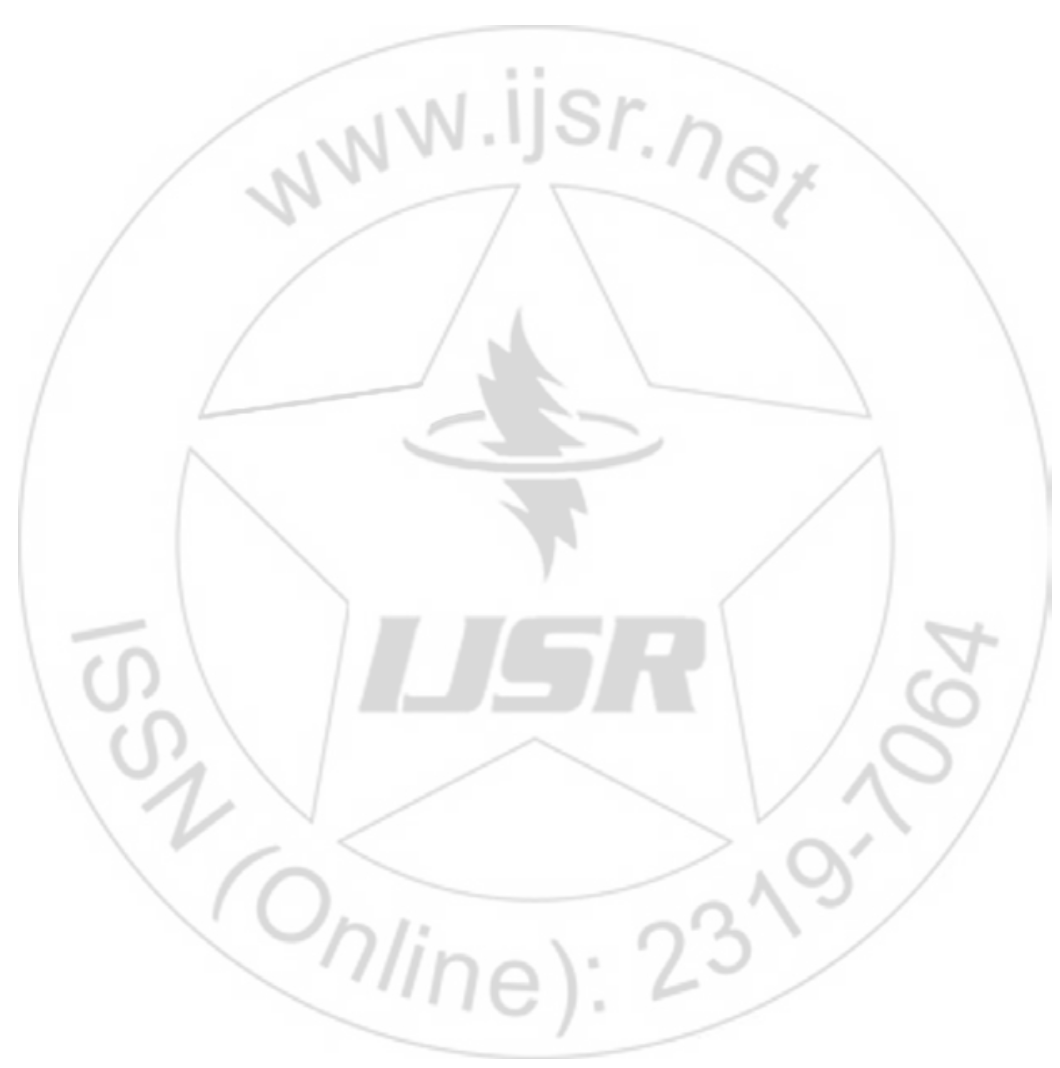

Volume 5 Issue 5, May 2016 